Vol. 3, No. 1, March 2021 e-ISSN: 2656-4882 p-ISSN: 2656-5935

\title{
Sistem Informasi Penyewaan Kapal Berbasis Web (Studi Kasus : PT. Servewell Offshore)
}

\author{
Yessy Yolanda ${ }^{1}$, Yena Puspitasari ${ }^{2}$, Novi Lestari ${ }^{3}$, \\ Nurullah Husufa 4
}

\author{
1Fakultas Ilmu Komputer ,Universitas Mercu Buana, Jakarta, Idnonesia \\ 2,3Program Studi Sistem Informasi, Universitas Mercu Buana, Jakarta, Indonesia \\ Email: ${ }^{1}$ yessyyoan@gmail.com, ${ }^{2}$ yenapuspitasari@gmail.com, ${ }^{3}$ novilestari041@gmail.com, \\ nnurul_husufa@mercubuana.ac.id,
}

\begin{abstract}
Abstrak
Transportasi laut sebagai bagian dari sistem transportasi nasional perlu dikembangkan dalam rangka mewujudkan Wawasan Nusantara yang mempersatukan seluruh wilayah Indonesia, termasuk lautan nusantara sebagai kesatuan wilayah nasional. Sistem transportasi yang efektif dan efisien serta terpadu antar moda transportasi, merupakan hal yang penting untuk menciptakan pola distribusi nasional yang handal dan dinamis. Tidak dapat dipungkiri bahwa sarana transportasi laut di Negara kepulauan seperti Indonesia telah menjadi tulang punggung utama pergerakan distribusi barang dalam skala besar dengan menggunakan kapal laut dan semakin banyaknya peluang untuk menyewakan kapal laut kepada customer untuk pendistribusian barang atau jasa. Ketatnya persaingan bisnis mengharuskan perusahaan perlu meningkatkan pelayanan terhadap customer dengan memperbaiki permasalahan yang sering terjadi pada saat penyewaan. Menggunakan model $W$ aterfall, UML,PHP,MYSQL dan framework Bootstrap dibuatlah sistem informasi penyewaan berbasis web. Sistem yang dibangun dapat membuat customer melakukan penyewaan kapal melalui website serta dapat melihat informasi kapal yang disediakan dan biaya sewa dari tiap kapal yang tersedia tanpa harus menghubungi bagian marketing perusahaan.
\end{abstract}

Kata kunci: Sistem Informasi, Aplikasi Penyewaan Kapal, Sistem Kapal, Bootstrap

\section{PENDAHULUAN}

Persaingan usaha dan perkembangan dunia bisnis yang semakin pesat mendorong suatu perusahaan untuk selalu meningkatkan kualitas dan pelayanan kepada konsumen nya agar perusahaan tersebut bisa bertahan dengan ketatnya persaingan bisnis. Kepuasan pelanggan menjadi tolak ukur keberhasilan perusahaan. Hal tersebut menuntut perusahaan untuk berinovasi dengan memanfaatkan kemajuan teknologi informasi [1]. 
p-ISSN: 2656-5935 http://journal-isi.org/index.php/isi e-ISSN: 2656-4882

Teknologi komputerisasi sangat memberikan kemudahan kepada kegiatan dan kinerja para penggunanya yang tak jarang dapat memberikan kenaikan tingkat efektifitas dan efisiensi di dalam melakukan pekerjaan penggunanya. Sistem yang telah terkomputerisasi dengan baik akan menghasilkan informasi jauh lebih baik juga dari sistem manual[2]. Teknologi banyak digunakan sebagai sarana promosi dan informasi khususnya pada bidang website yang saat ini sangat berperan dalam penyempaian informasi. Website mampu memberikan informasi menjadi lebih efisien dan up to date [3]. Sistem informasi adalah suatu elemen-elemen yang saling berinteraksi secara sistematis dan teratur untuk menciptakan dan membentuk aliran informasi yang akan mendukung pembuatan keputusan dan melakukan kontrol terhadap jalannya perusahaan[4].

PT. Servewell Offshore adalah sebuah perusahaan yang bergerak di bidang jasa penyewaan kapal. Jenis kapal yang disewakan perusahaan diantaranya crew boat, tug boat dan utility boat. Kapal-kapal tersebut digunakan oleh penyewa untuk mendukung kegiatan offshore para penyewa. Masalah yang sering terjadi pada penyewaan diantaranya, Admin dan customer kesulitan untuk memeriksa status ketersediaan kapal, karena sistem yang ada masih mencatat manual didalam buku. Penyewa tidak mengetahui informasi detail mengenai kapal-kapal yang dimiliki oleh perusahaan. Bagian marketing harus memberikan informasi mengenai kapal yang akan disewa oleh penyewa melalui e-mail. Penyewa tidak mengetahui apakah penyewaan kapal yang mereka ajukan disetujui Direktur pemilik kapal sewa. Bagian maintenance kesulitan untuk mengetahui mana dulu complain kapal yang harus dikerjakan atau didahulukan ketika kapal telah disewa oleh customer karena pencatatan masih dilakukan manual.

Berdasarkan permasalahan di atas, maka dibuatlah sebuah sistem informasi yang mempermudah penyewa dan perusahaan untuk mengakses sistem penyewaan kapal melalui website dan mempercepat proses pemberian informasi mengenai kapal-kapal yang tersedia di PT. Servewell Offshore kepada penyewa. Metode pengembangan aplikasi untuk menyelesaikan masalah di atas adalah dengan menggunakan metode waterfall. Bahasa pemrograman yang digunakan dalam penelitian ini menggunakan PHP dan penggunaan framework bootstrap untuk merancang tampilan web.

\section{METODOLOGI PENELITIAN}

Ada beberapa metode yang digunakan dalam penelitian ini. Berikut uraian dari metode-metode yang dipakai.

\subsection{Metode Pengumpulan Data}

Metode pengumpulan data yang digunakan dalam penelitian ini terdiri dari beberapa bagian, yaitu: 
1) Observasi

Pada metode ini dilakukan penelitian langsung di PT Servewell Offshore untuk mengetahui proses bisnis yang sedang berjalan.

2) Wawancara

Pada metode ini, pengumpulan data dengan penulisan melakukan wawancara khususnya pada setiap divisi terkait di PT Servewell Offshore.

3) Studi Pustaka

Metode ini dilakukan untuk mengumpulkan data dengan cara membaca berbagai macam artikel, dan jurnal yang berhubungan dengan sistem yang akan dibuat.

\subsection{Metode Waterfall}

Penelitian ini menggunakan rekayasa perangkat lunak model waterfall. Model ini lebih sederhana dibandingkan dengan yang lain dan cocok dengan perancangan ini. Model waterfall sering juga disebut model sekuensial liner (sequential linier) atau alur hidup klasik (classic life cycle). Model waterfall menyediakan pendekatan alur hidup perangkat lunak secara sekuensial atau berturut-turut dimulai dari analisis, desain, pengodean, pengujian dan tahap pendukung (support)[5].

\subsection{UML}

Unified Modelling Language (UML) adalah sebuah standar bahasa yang biasa digunakan di dunia industri untuk mengartikan requirement, membuat analisis dan perancangan, serta menggambarkan arsitektur dalam pemrograman berorientasi objek [6]. Use case merupakan teknik pemodelan untuk merumuskan kebutuhan fungsional system[8].

\subsection{Black Box Testing}

Black box testing merupakan pengujian kualitas perangkat lunak yang berfokus pada fungsionalitas perangkat lunak[7].

\subsection{Metode PIECES}

Metode PIECES merupakan metode yang digunakan untuk mengetahui permasalahan-permasalahan yang ada pada suatu sistem dan digunakan sebagai bahan referensi dan kontrol untuk perubahan sistem itu sendiri[9].

\section{HASIL DAN PEMBAHASAN}

\subsection{Analisa Proses Bisnis}

Berikut ini merupakan analisis proses bisnis penyewaan kapal pada sistem yang berjalan di PT Servewell Offshore: 
Vol. 3, No. 1, March 2021

p-ISSN: 2656-5935 http://journal-isi.org/index.php/isi e-ISSN: 2656-4882

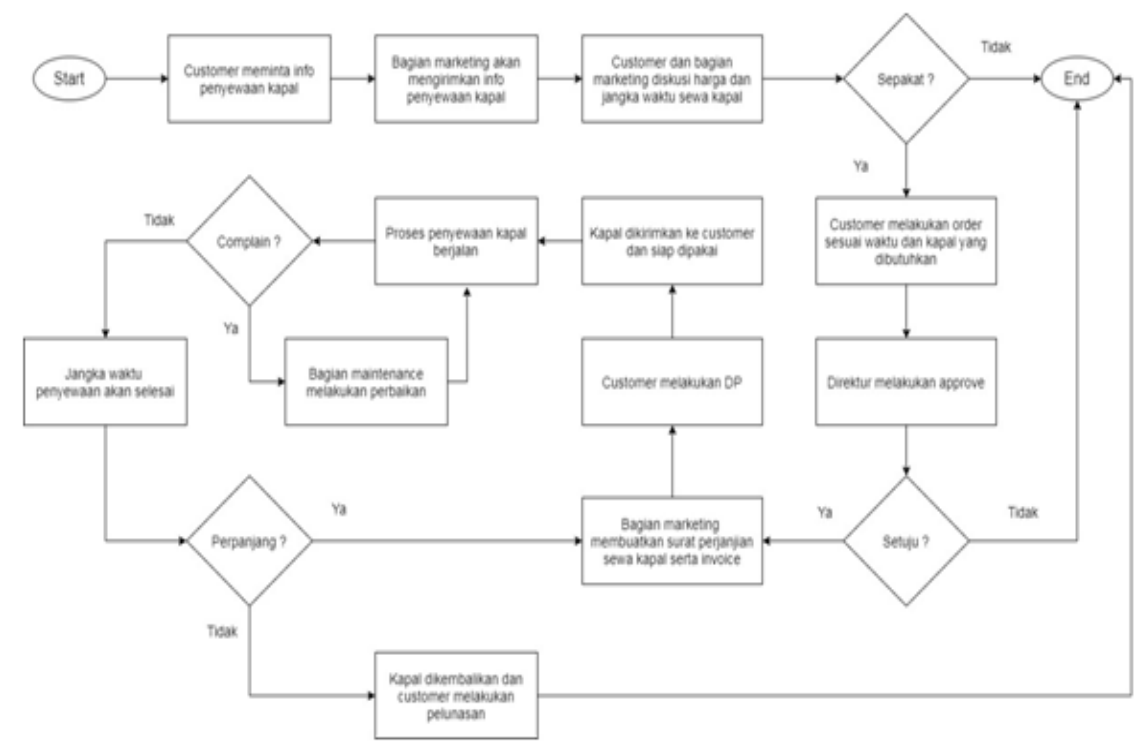

Gambar 1. Alur Proses Penyewaan Kapal

Penjelasan dari alur proses penyewaan kapal:

Dimulai dengan, customer menelepon atau mengirimkan e-mail ke bagian marketing perusahaan untuk mencari tahu mengenai informasi kapal. Bagian marketing akan menanggapi permintaan customer melalui e-mail atau menghubungi secara langsung. Setelah itu, pihak customer dan bagian marketing akan melakukan diskusi mengenai harga sewa kapal serta jangka waktu berapa lama kapal akan dipakai oleh customer. Apabila sepakat, maka customer akan melakukan pemesanan dan Direktur melakukan persetujuan approve atau tidak. Jika disetujui oleh Direktur maka proses penyewaan bisa dilanjutkan, sedangkan jika tidak maka transaksi dibatalkan. Selanjutnya bagian marketing akan membuatkan surat perjanjian antara perusahaan dengan customer serta invoice sesuai dengan kesepakatan yang sudah disetujui.

Customer melakukan pembayaran DP sesuai kesepakatan dan kapal akan dipersiapkan oleh bagian maintenance, operation dan crewing. Setelah semua sudah dilengkapi, kapal akan dikirimkan ke customer dan siap untuk dipakai. Selama penyewaan, jika ada complain dari customer maka bagian maintenance akan melakukan perbaikan. Saat masa sewa akan berakhir maka akan ada komunikasi antara customer dengan bagian marketing apakah masa sewa kapal akan diperpanjang atau tidak. Kalau diperpanjang, maka akan dibuatkan surat perjanjian perpanjangan kapal dan kalau tidak diperpanjang maka kapal akan dikembalikan kepada perusahaan serta customer melakukan pelunasan dan perjanjian sewa menyewa berakhir. 
Vol. 3, No. 1, March 2021

p-ISSN: 2656-5935 http://journal-isi.org/index.php/isi e-ISSN: 2656-4882

\subsection{Identifikasi Masalah}

Untuk mengidentifikasi permasalahan, penulis menggunakan metode analisa PIECES untuk mengidentifikasi kekuatan, kelemahan, peluang dan ancaman selama mengembangkan penyewaan kapal di PT Servewell Offshore :

Tabel 1. Analisa PIECES

\begin{tabular}{|c|c|c|}
\hline Kriteria & Masalah & Solusi \\
\hline Performance & $\begin{array}{l}\text { - Penyewa tidak } \\
\text { mengetahui informasi } \\
\text { detail mengenai spesifikasi } \\
\text { kapal yang dimiliki oleh } \\
\text { perusahaan. } \\
\text { - Penyewa } \\
\text { mengetahui info status } \\
\text { kapal yang dibutuhkan } \\
\text { tersedia atau tidak. }\end{array}$ & $\begin{array}{l}\text { - Dibuatkan halaman untuk } \\
\text { menampilkan data kapal agar } \\
\text { penyewa bisa mengetahui } \\
\text { informasi detail mengenai } \\
\text { spesifikasi kapal dan } \\
\text { mengetahui status kapal } \\
\text { tersedia atau tidak. }\end{array}$ \\
\hline Information & $\begin{array}{l}\text { - Penyewa dan marketing } \\
\text { diskusi masalah harga. }\end{array}$ & $\begin{array}{l}\text { - Ditampilkan di dalam halaman } \\
\text { web informasi mengenai harga } \\
\text { sewa kapal. }\end{array}$ \\
\hline Economics & $\begin{array}{l}\text { - Data-data seperti invoice } \\
\text { penyewaan dan nota } \\
\text { pembayaran } \\
\text { disimpan dalam bentuk } \\
\text { kertas. }\end{array}$ & $\begin{array}{l}\text { - Data-data tersimpan dalam } \\
\text { database system. }\end{array}$ \\
\hline Control & $\begin{array}{l}\text { - Pengaturan crew sebelum } \\
\text { kapal di kirim masih } \\
\text { diatur secara manual } \\
\text { dengan membuat daftar } \\
\text { crew. }\end{array}$ & $\begin{array}{l}\text { - Dibuatkan dalam sistem agar } \\
\text { pengaturan crew dapat } \\
\text { dilakukan di web. }\end{array}$ \\
\hline Efficiency & $\begin{array}{l}\text { - Bagian marketing harus } \\
\text { mengirimkan email } \\
\text { kepada penyewa } \\
\text { mengenai info kapal yang } \\
\text { dibutuhkan. } \\
\text { - Buat surat perjanjian } \\
\text { antara penyewa dan } \\
\text { perusahaan. } \\
\text { - Proses approve masih } \\
\text { dilakukan secara manual } \\
\text { oleh Direktur. }\end{array}$ & $\begin{array}{l}\text { - Dibuatkan sistem dengan } \\
\text { berisikan informasi detail kapal } \\
\text { agar bagian marketing tidak } \\
\text { harus mengirim e-mail. } \\
\text { - Dibuatkan sistem yang dapat } \\
\text { mencetak data penyewaan } \\
\text { kapal sesuai dari order yang } \\
\text { dilakukan penyewa. } \\
\text { - Terdapat sistem approval } \\
\text { untuk Direktur. }\end{array}$ \\
\hline Service & - Terdapat sistem approval & - Dibuatkan \\
\hline
\end{tabular}


Vol. 3, No. 1, March 2021

p-ISSN: 2656-5935 http://journal-isi.org/index.php/isi e-ISSN: 2656-4882

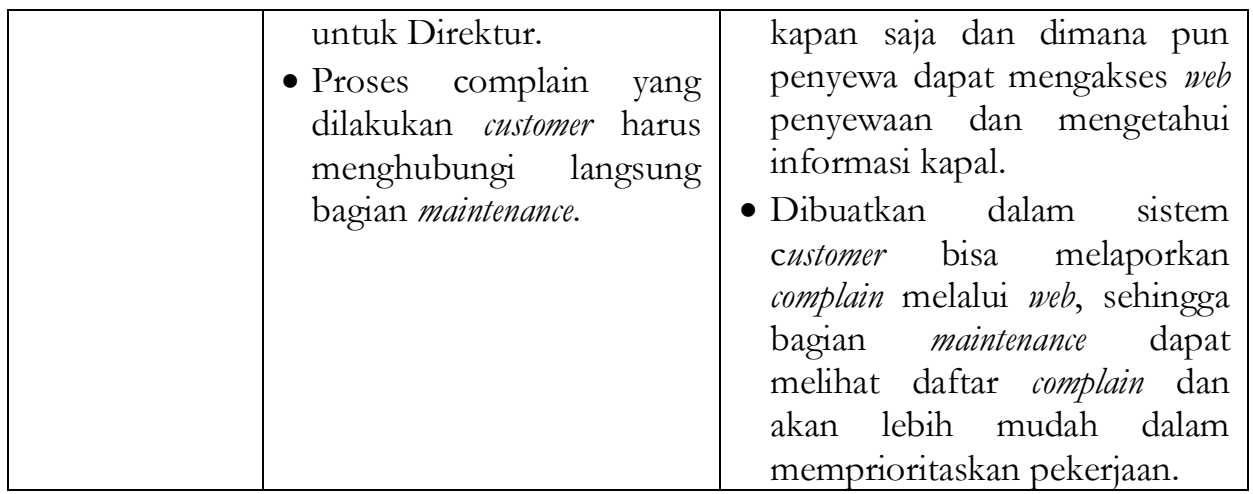

\subsection{Use Case}

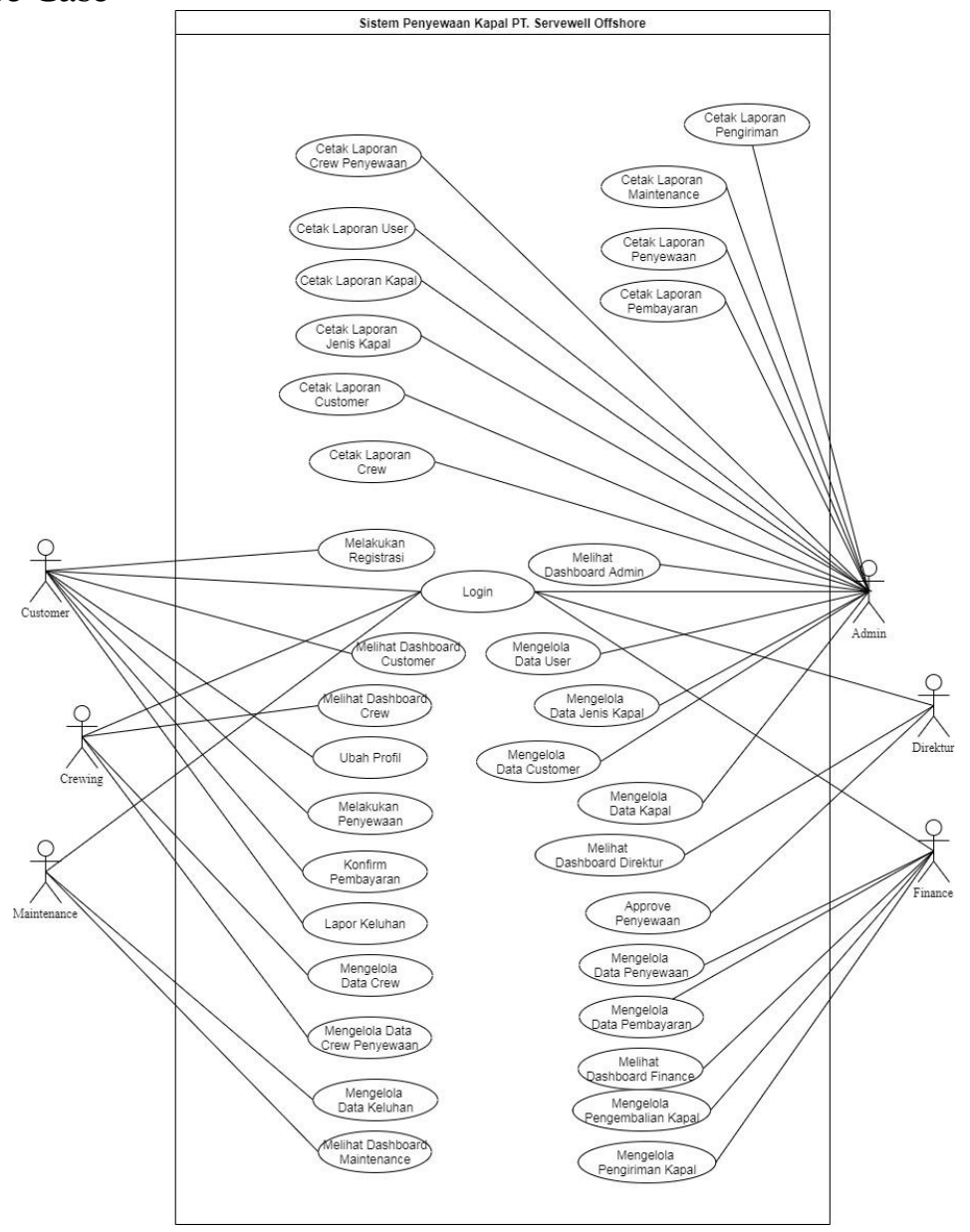

Gambar 2. Diagram Use Case 
Vol. 3, No. 1, March 2021

p-ISSN: 2656-5935 http://journal-isi.org/index.php/isi e-ISSN: 2656-4882

Pada use case diagram, digambarkan penggunaan sistem oleh aktor untuk mendukung penerapan sistem informasi penyewaan kapal berbasis website, dengan rincian usecase dari masing-masing aktor sebagai berikut:

1) Admin, Admin dapat login, mengelola data user, mengelola data jenis kapal, mengelola data kapal, mengelola data customer dan melihat laporan.

2) Customer, Customer dapat login, melakukan registrasi, melakukan update profil, melakukan penyewaan, melakukan konfirmasi pembayaran dan melakukan laporan keluhan.

3) Direktur, Direktur dapat login, melakukan update profil dan melakukan approve penyewaan.

4) Maintenance, Maintenance dapat login, melakukan update profil., melihat data penyewaan, mengelola data keluhan dan melihat laporan keluhan.

5) Crewing, Crewing dapat login, dari melakukan update profil, melihat data penyewaan dan mengelola data crew penyewaan.

6) Finance, Finance dapat login, melakukan update profil, mengelola data penyewaan, mengelola data pembayaran, mengelola pengiriman kapal, dan mengelola pengembalian kapal.

\subsection{Class Diagram}

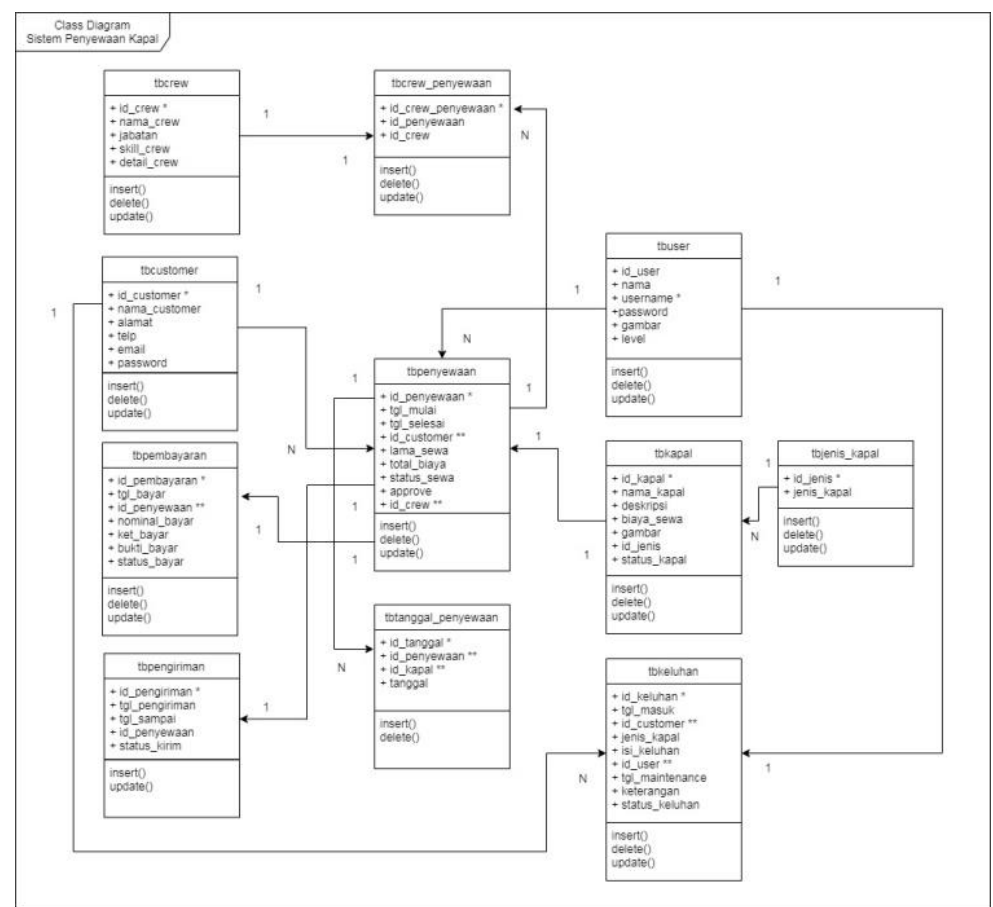

Gambar 3. Class Diagram 
Class Diagram pada Sistem Penyewaan Kapal terdiri dari Tbuser dimana class ini untuk menyimpan data user. Tbcrew dimana Class ini untuk menyimpan data crew. Tbcrew_penyewaan dimana class ini digunakan untuk menyimpan data crew pada transaksi penyewaan dan memerlukan oleh tbcrew dan tbpenyewaan. Tbcustomer dimana Class ini digunakan untuk menyimpan data customer. Tbjenis_kapal dimana Class ini digunakan untuk menyimpan data jenis kapal. Tbkapal dimana Class ini digunakan untuk menyimpan data kapal. Dan membutuhkan tbjenis_kapal. Tbkeluhan dimana Class ini digunakan untuk menyimpan data keluhan. Class ini memerlukan tbpenyewaan, tbcustomer, tbkapal dan tbuser. Tbpembayaran dimana Class digunakan untuk menyimpan data pembayaran. Class ini memerlukan tbpenyewaan. Tbpengiriman dimana Class ini digunakan untuk menyimpan data pengiriman kapal dimana Class ini memerlukan tbpenyewaan. Tbpenyewaan dimana Class ini digunakan untuk menyimpan data penyewaan kapal. Class ini memerlukan tbcustomer dan tbkapal. Tbtanggal_penyewaan dimana Class ini digunakan untuk menyimpan data tanggal sewa. Class ini memerlukan tbpenyewaan dan tbkapal.

\subsection{Desain Aplikasi}

1) Tampilan Halaman Utama Customer
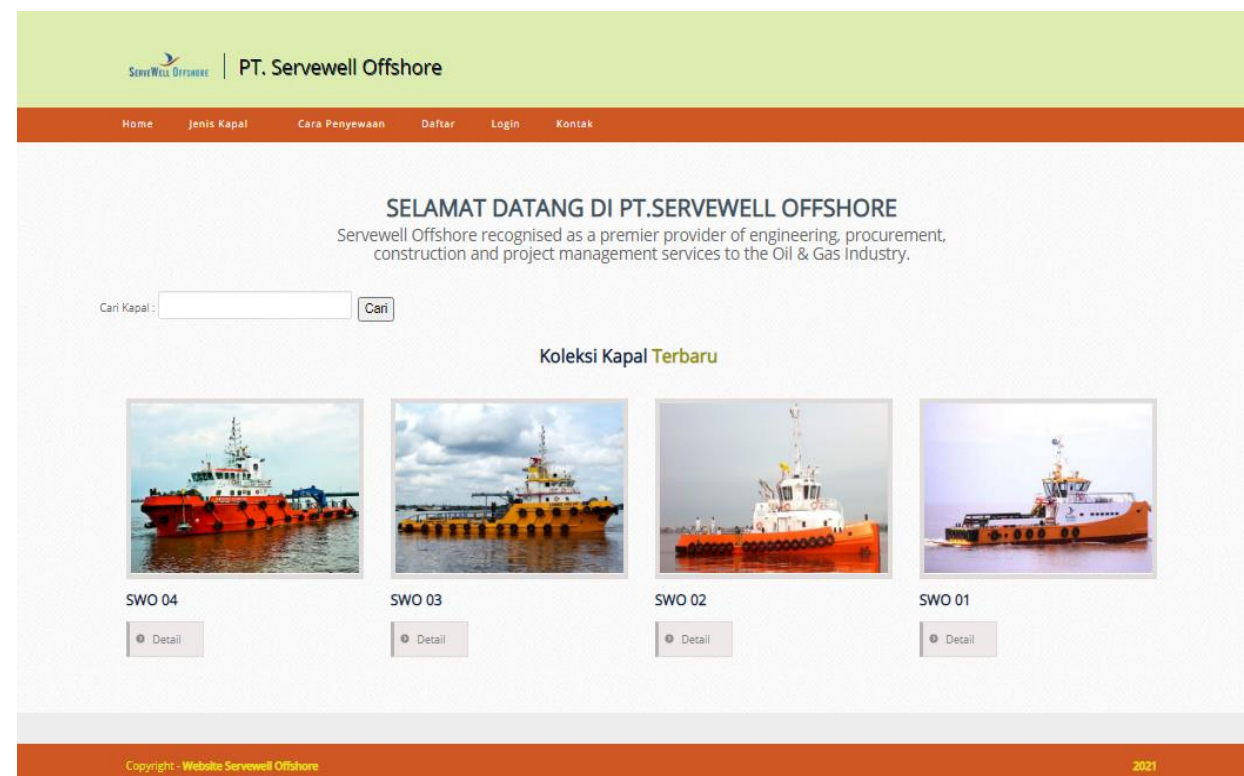

Gambar 4. Tampilan Halaman Utama Customer

Halaman ini adalah tampilan utama saat customer membuka website. Pada tampilan utama menampilkan enam menu dan gambar kapal terbaru. 
2) Tampilan Halaman Jenis Kapal
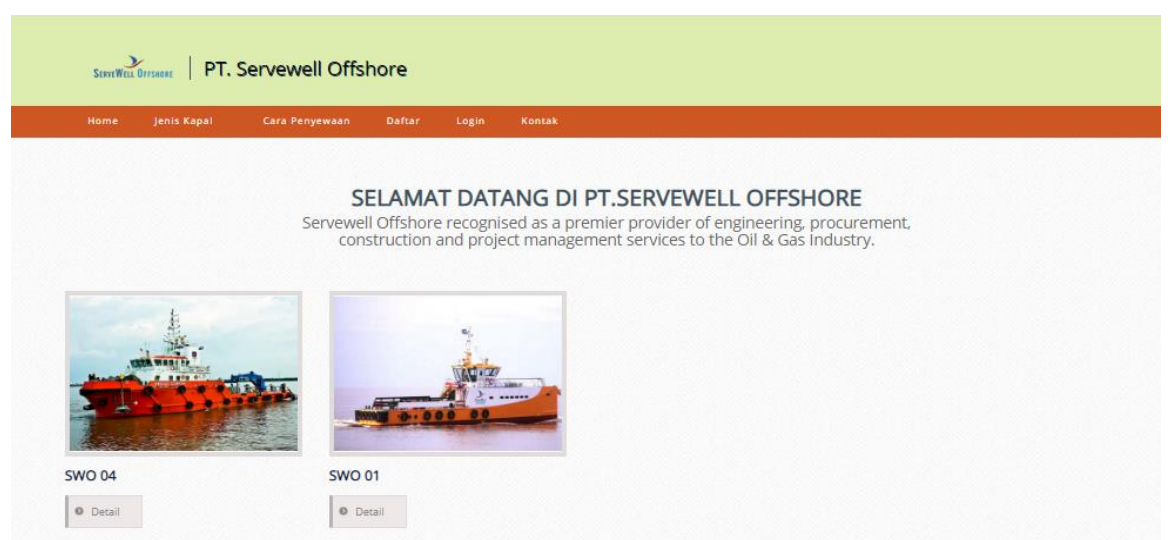

Gambar 5. Tampilan Halaman Jenis Kapal

Halaman ini adalah halaman jenis kapal. Pada tampilan ini menampilkan gambar kapal sesuai dengan jenis yang dipilih oleh user.

3) Tampilan Halaman Registrasi

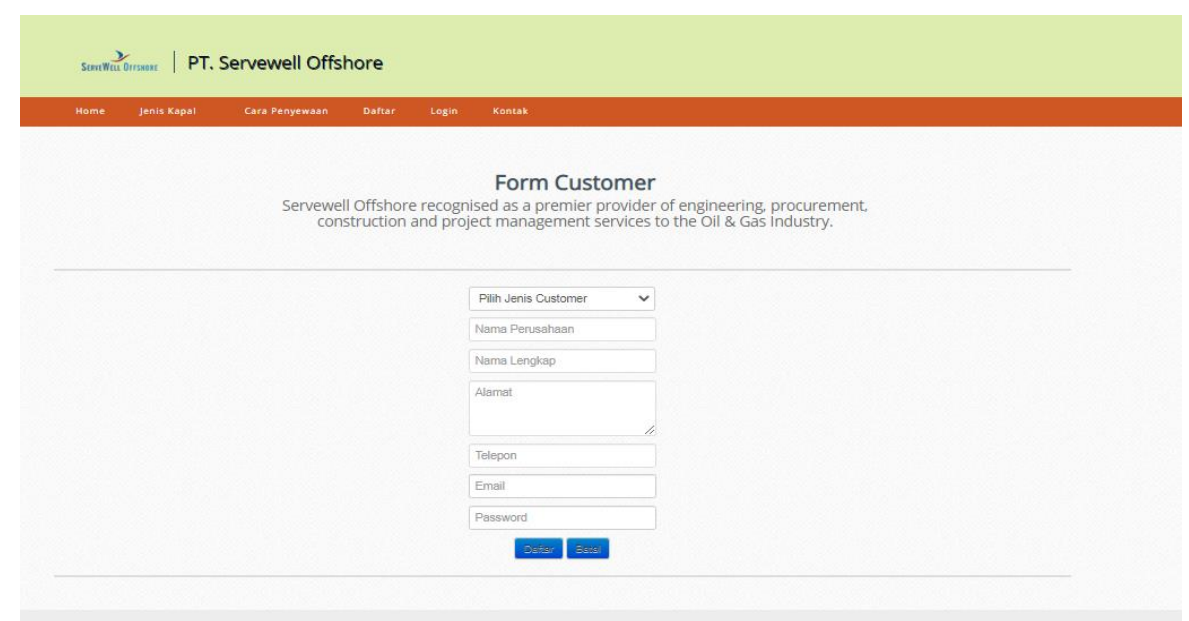

Gambar 6. Tampilan Halaman Registrasi

Halaman ini adalah tampilan daftar customer. Pada tampilan ini menampilkan form customer melakukan registrasi. 
4) Tampilan Halaman Login

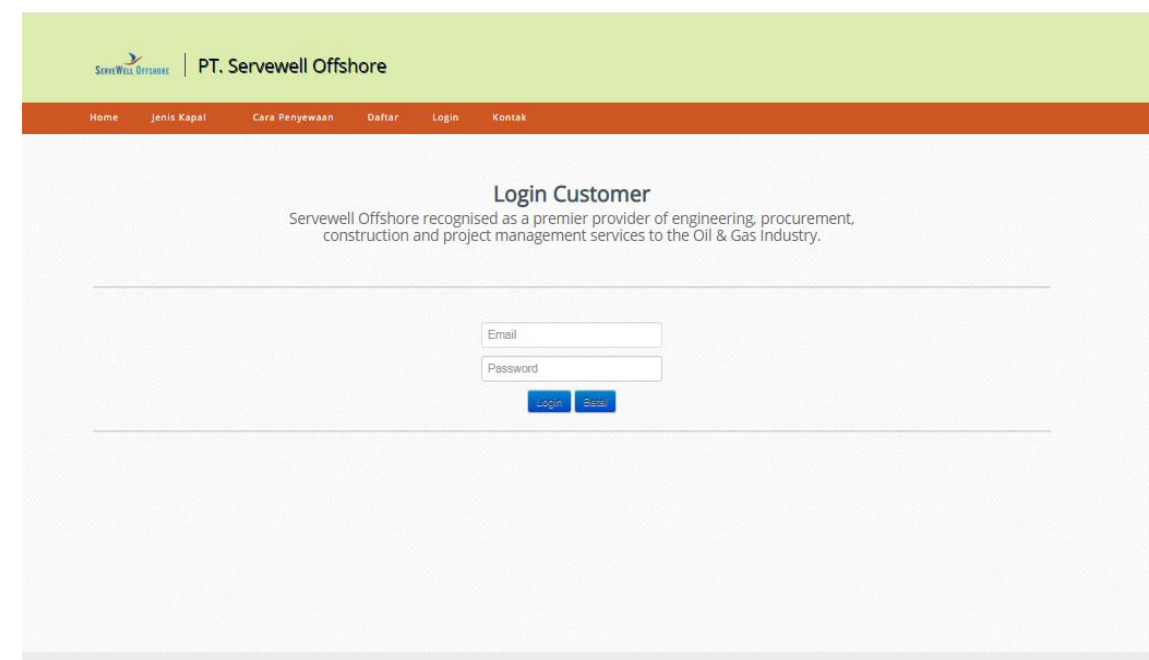

Gambar 7. Tampilan Halaman Login

Halaman ini adalah tampilan login customer. Pada tampilan ini menampilkan form login yang digunakan customer masuk kedalam sistem dan melakukan penyewaan.

5) Tampilan Halaman Penyewaan Kapal

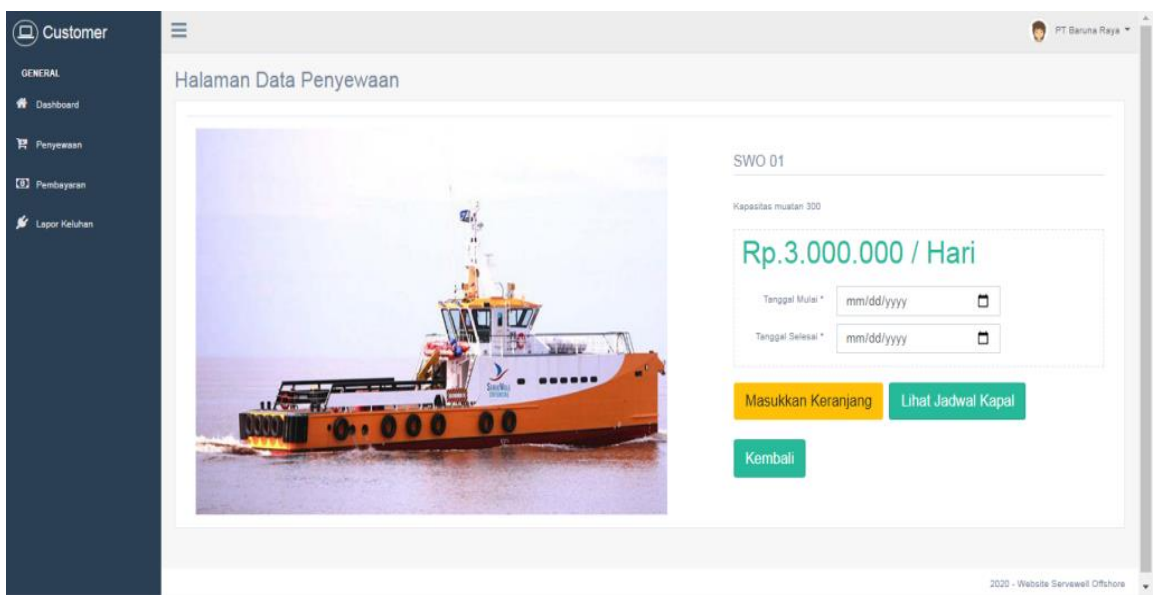

Gambar 8. Tampilan Halaman Penyewaan Kapal

Halaman ini adalah tampilan pada saat customer melakukan penyewaan kapal. Customer dapat memilih tanggal mulai dan tanggal selesai sewa kapal. Dan juga dapat melihat jadwal kapal untuk mengetahui kapal tersebut tersedia atau tidak. 
Journal of Information Systems and Informatics

Vol. 3, No. 1, March 2021

p-ISSN: 2656-5935 http://journal-isi.org/index.php/isi

e-ISSN: 2656-4882

6) Tampilan Halaman Approve Penyewaan Kapal

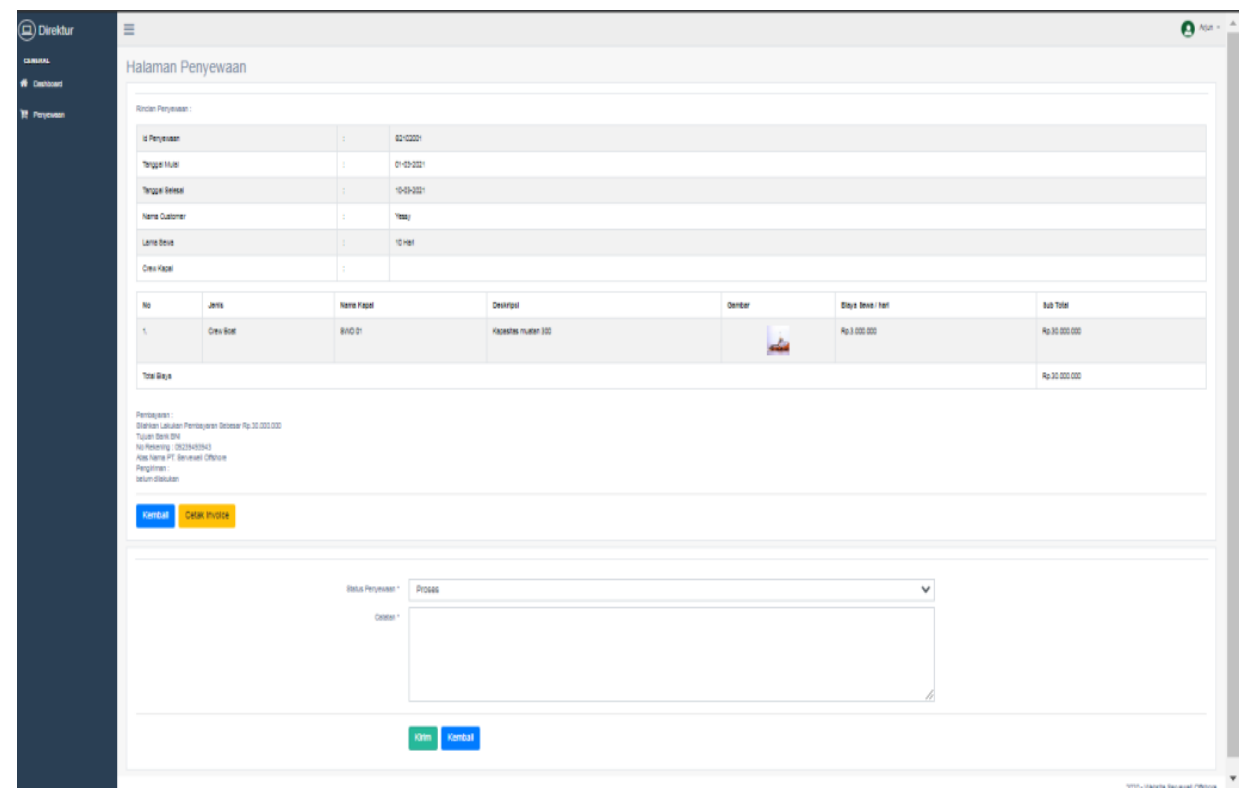

Gambar 9. Tampilan Halaman Approve Penyewaan Kapal

Halaman ini adalah tampilan untuk approve penyewaan kapal yang di lakukan oleh Direktur. Direktur dapat menerima atau menolak penyewaan kapal dengan memilih status penyewaan dan memberikan catatan pada kolom yang di sediakan.

7) Tampilan Halaman Mengelola Data User

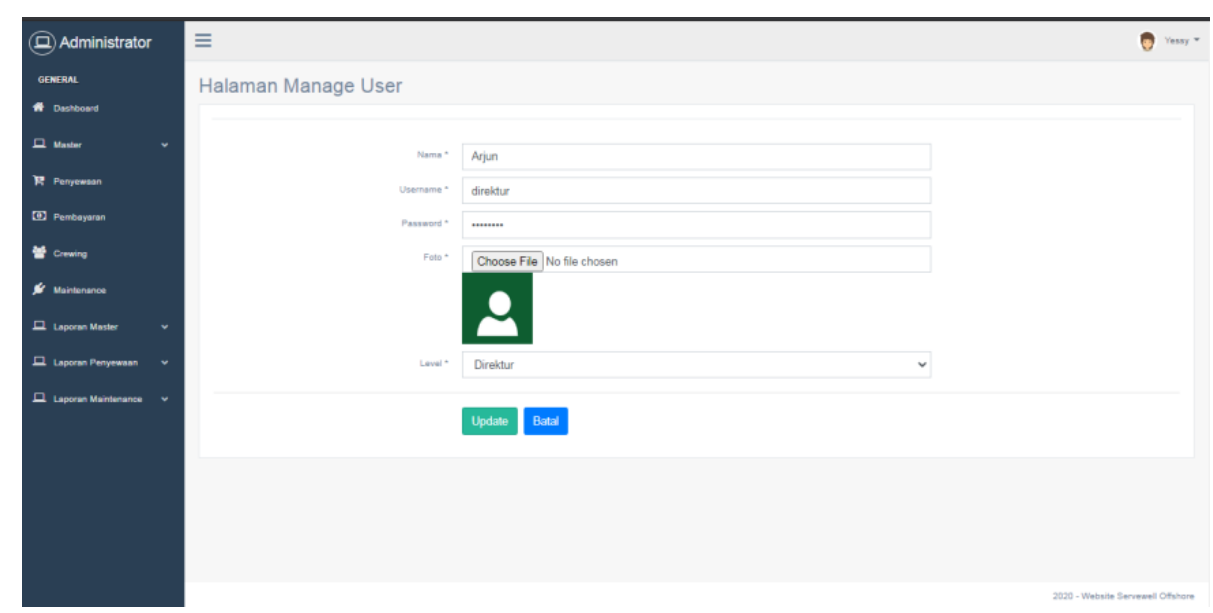

Gambar 10. Tampilan Halaman Mengelola Data User 
Halaman ini digunakan untuk mengelola data user. Admin dapat menambahkan data user melalui tombol "tambah data", mengupdate data user dengan memilih tombol "update" dan menghapus data user dengan mengklik icon "delete".

8) Tampilan Halaman Mengelola Data Kapal

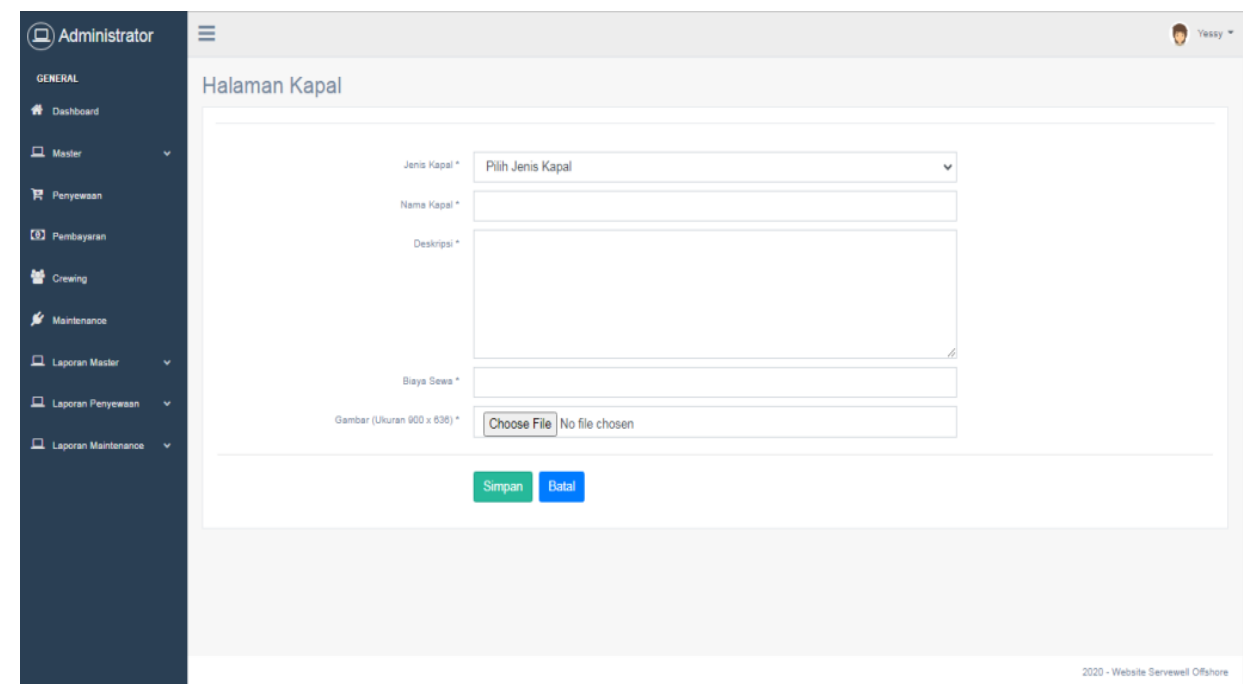

Gambar 11. Tampilan Halaman Mengelola Data kapal

Halaman ini digunakan untuk mengelola data kapal. Admin dapat menambahkan data kapal melalui tombol "tambah data", mengupdate data kapal dengan memilih tombol "update" dan menghapus data kapal dengan mengklik icon "delete".

9) Tampilan Halaman Mengelola Data Customer

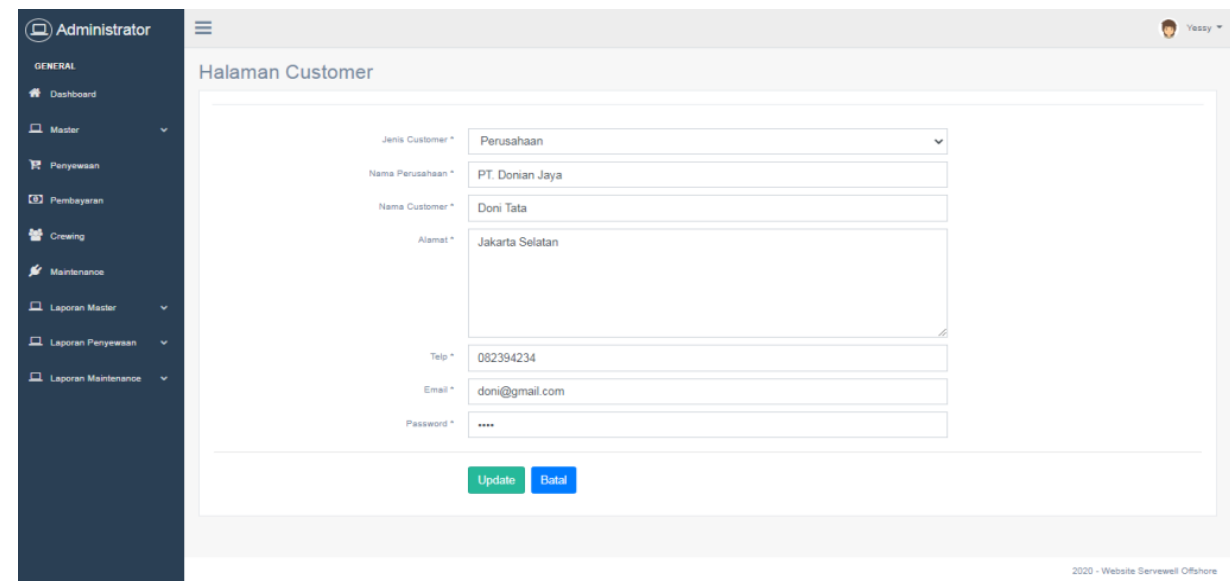

Gambar 12. Tampilan Halaman Mengelola Data Customer 
Halaman ini digunakan untuk mengelola data costumer. Admin dapat menambahkan mengupdate data user dengan memilih tombol "update" dan menghapus data user dengan mengklik icon "delete".

10) Tampilan Halaman Customer Lapor Keluhan

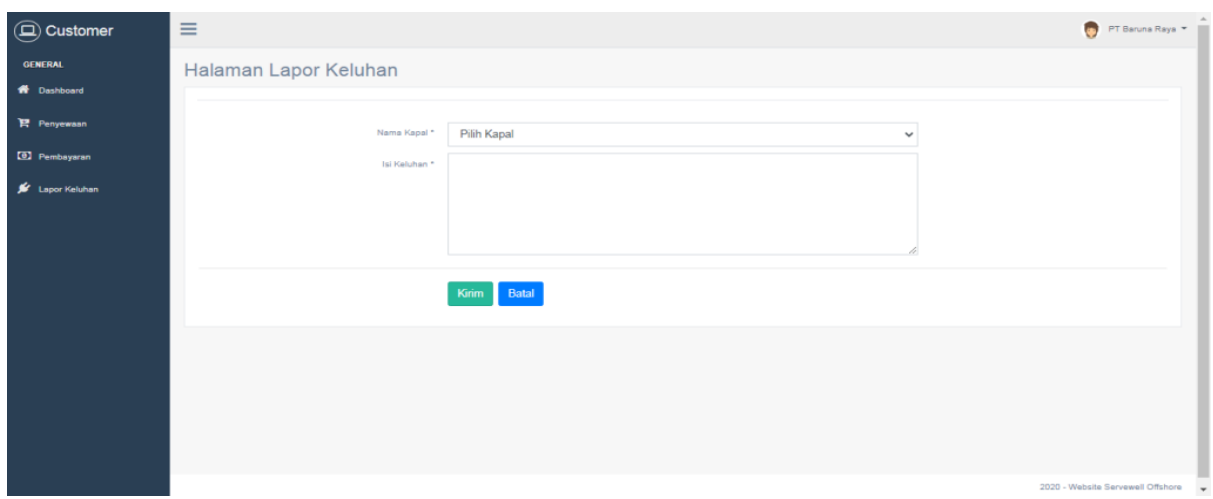

Gambar 13. Tampilan Halaman Customer Lapor Keluhan

Halaman ini adalah tampilan untuk lapor keluhan yang dilakukan oleh Customer. Customer dapat memilih nama kapal yang akan diajukan untuk perbaikan dan juga dapat mengetik keluhan di kolom isi keluhan yang telah disediakan.

11) Tampilan Halaman Maintenance Mengelola Data Keluhan

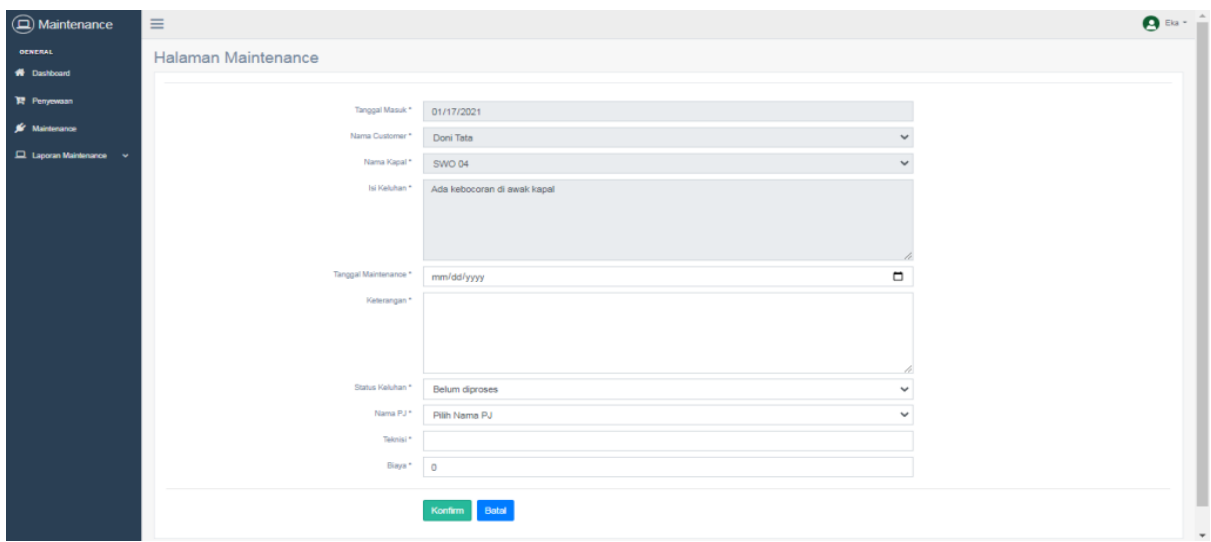

Gambar 14. Tampilan Halaman Maintenance Mengelola Data Keluhan

Halaman ini adalah tampilan untuk mengelola data keluhan yang dilakukan oleh maintenance. Pada halaman ini maintenance dapat mengisi tanggal maintenance, memberikan keterangan, mengubah status keluhan dan menginput biaya yang dibutuhkan apabila ada. 
12) Tampilan Halaman Customer Mengubah Profil
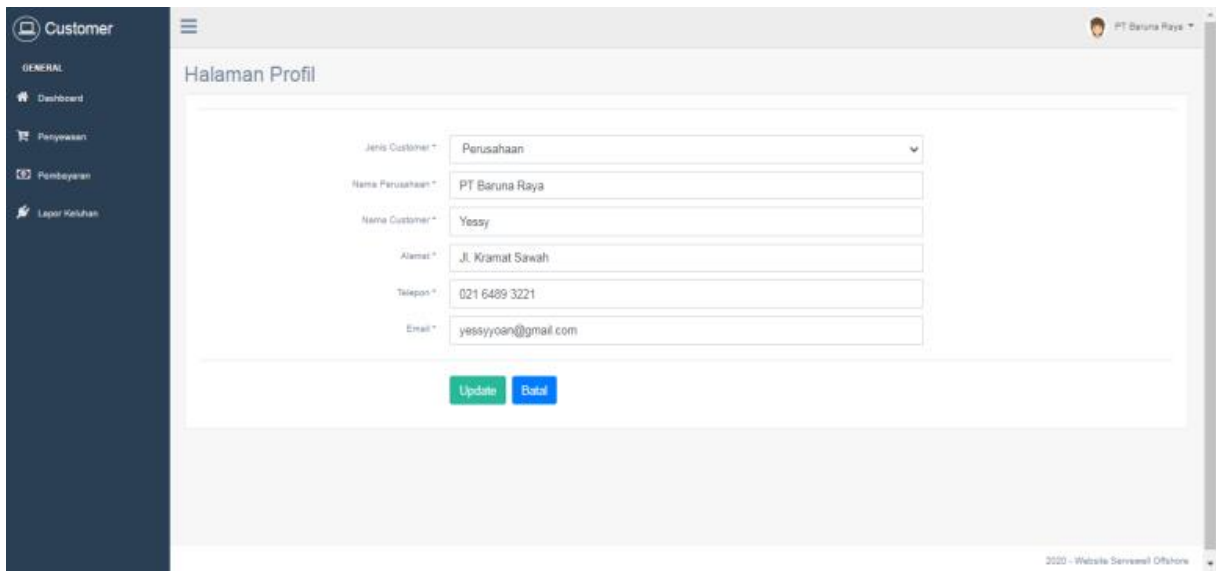

Gambar 15. Tampilan Halaman Customer Mengubah Profil

Halaman ini adalah tampilan untuk mengubah profil yang dilakukan oleh customer. Pada halaman ini customer dapat mengupdate data profil.

13) Tampilan Halaman Customer Upload Bukti Pembayaran
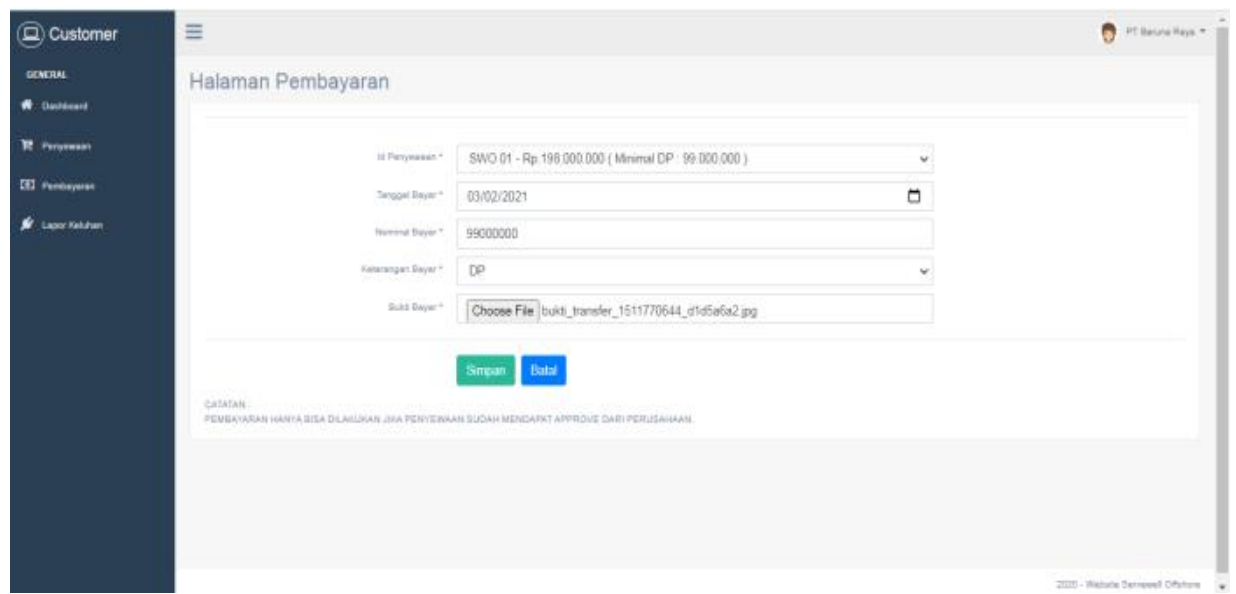

Gambar 16. Tampilan Halaman Customer Upload Bukti Pembayaran

Halaman ini adalah tampilan pada saat customer melakukan pembayaran. Customer dapat memilih kapal yang akan dibayar, memilih keterangan bayar, menginput jumlah pembayaran serta mengupload bukti bayar. 
Vol. 3, No. 1, March 2021

p-ISSN: 2656-5935 http://journal-isi.org/index.php/isi e-ISSN: 2656-4882

\subsection{Black Box Testing Aplikasi}

Pengujian sistem dilakukan menggunakan metode Black Box Testing yang berfokus pada fungsionalitas aplikasi dan keluaran yang dihasilkan, terlihat pada tabel 1.

Tabel 1. Black Box Testing

\begin{tabular}{|c|c|c|c|c|}
\hline No & Antarmuka & Skenario Uji & Hasil yang diharapkan & Hasil Uji \\
\hline 1 & $\begin{array}{l}\text { Transaksi } \\
\text { Penyewaan } \\
\text { Kapal }\end{array}$ & $\begin{array}{l}\text { Customer } \\
\text { melakukan } \\
\text { order } \\
\text { penyewaan } \\
\text { kapal }\end{array}$ & $\begin{array}{l}\text { Kapal berhasil di pesan } \\
\text { dan muncul notifikasi. } \\
\text { Data berhasil disimpan dan } \\
\text { ditampilkan di halaman } \\
\text { penyewaan }\end{array}$ & Berhasil \\
\hline 2 & Pembayaran & $\begin{array}{l}\text { Finance } \\
\text { menolak } \\
\text { pembayaran } \\
\text { dan } \\
\text { memberikan } \\
\text { alasan } \\
\text { penolakan }\end{array}$ & $\begin{array}{l}\text { Pembayaran berhasil } \\
\text { ditolak dan data muncul di } \\
\text { halaman pembayaran } \\
\text { customer juga }\end{array}$ & Berhasil \\
\hline 3 & Penyewaan & $\begin{array}{l}\text { Mengubah } \\
\text { status } \\
\text { penyewaan } \\
\text { kapal dari } \\
\text { halaman } \\
\text { penyewaan } \\
\text { kapal }\end{array}$ & $\begin{array}{l}\text { Status kapal berhasil } \\
\text { diubah }\end{array}$ & Berhasil \\
\hline 4 & $\begin{array}{l}\text { Konfirmasi } \\
\text { Pembayaran }\end{array}$ & $\begin{array}{l}\text { Mengirim bukti } \\
\text { pembayaran }\end{array}$ & $\begin{array}{l}\text { Bukti pembayaran berhasil } \\
\text { dikirim. }\end{array}$ & Berhasil \\
\hline 5 & Lapor Keluhan & $\begin{array}{l}\text { Melaporkan } \\
\text { keluhan saat } \\
\text { penyewaan }\end{array}$ & $\begin{array}{l}\text { Data keluhan berhasil } \\
\text { dilaporkan }\end{array}$ & Berhasil \\
\hline 6 & $\begin{array}{l}\text { Respon } \\
\text { Keluhan }\end{array}$ & $\begin{array}{l}\text { Merespon } \\
\text { keluhan } \\
\text { customer }\end{array}$ & $\begin{array}{l}\text { Data keluhan berhasil } \\
\text { direspon }\end{array}$ & Berhasil \\
\hline 7 & $\begin{array}{l}\text { Approval } \\
\text { penyewaan }\end{array}$ & $\begin{array}{l}\text { Memberi } \\
\text { approve order } \\
\text { penyewaan } \\
\end{array}$ & $\begin{array}{l}\text { Order penyewaan berhasil } \\
\text { di approve }\end{array}$ & Berhasil \\
\hline 8 & $\begin{array}{l}\text { Approval } \\
\text { penyewaan }\end{array}$ & $\begin{array}{l}\text { Menolak order } \\
\text { penyewaan }\end{array}$ & $\begin{array}{l}\text { Order penyewaan berhasil } \\
\text { di ditolak }\end{array}$ & Berhasil \\
\hline
\end{tabular}

\section{KESIMPULAN}

Dengan dibuatnya sistem informasi penyewaan ini membuat customer dapat dengan mudah melakukan penyewaan kapal melalui website serta dapat melihat informasi kapal yang disediakan serta biaya sewa dari tiap kapal yang tersedia di 
PT. Servewell Offshore tanpa harus menghubungi bagian marketing perusahaan. Marketing juga dapat mengetahui serta memiliki daftar-daftar nama customer melalui registrasi yang dilakukan oleh customer melalui website yang tersedia dan Direktur dengan mudah memantau serta melakukan approve terhadap penyewaan kapal melalui sistem yang ada.

\section{DAFTAR PUSTAKA}

[1] I. Septavia, R. E. Gunadhi, and R. Kurniawati, "Sistem Informasi Penyewaan Mobil Berbasis Web," pp. 534-540, 2005.

[2] E. Nurfitriana, W. Apriliah, H. Ferliyanti, and H. Basri, "Implementasi Model Waterfall Dalam Sistem Informasi Akuntansi Piutang Jasa Penyewaan Kendaraan Pada Pt .," vol. 15, no. April 2020, pp. 36-45.

[3] D. A. N. Informasi, "Perancangan Website Sebagai Media Promosi," vol. 3, no. 1, pp. 82-86, 2018.

[4] S. K. BSD Oetomo, Perencanaan \& Pembangunan Sistem Informasi. 2002.

[5] A. S. Rosa and M. Shalauddin, Modul Pembelajaran Rekayasa Perangkat Lunake (Terstruktur Dan Berorientasi Objek). Informatika Bandung, 2011.

[6] S. Monalisa et al., "Sistem Informasi Monitoring Perjalanan Kapal," vol. 5, no. 2, pp. 171-183, 2019.

[7] L. Setiyani, "Pengujian Sistem Informasi Inventory Pada Perusahaan Distributor Farmasi Menggunakan Metode Black Box Testing," Techno Xplore J. Ilmu Komput. dan Teknol. Inf., vol. 4, no. 1, pp. 1-9, 2019, doi: 10.36805/technoxplore.v4i1.539.

[8] A. Mutedi, "Rancang Bangun Aplikasi Booking Kapal untuk Berwisata dan Memancing Berbasis Android (Design and Build Ship Booking Application for Traveling \& Fishing on an Android basis )," vol. 1, no. 3, pp. 213-220, 2019.

[9] Lukman Hakim and T. Pertiwi, "Analisis Tingkat Kepuasan Pengguna Terhadap Website Stkip Pgri Lubuklinggau Menggunakan Metode Pieces," J. Teknol. Infomasi dan Komput. Politek. Sekayu, vol. IX, 2018. 